\title{
Problems and future of electronic textbooks and electronic educational resources in technical college
}

\author{
Dmitry Kulikov ${ }^{1, *}$ \\ ${ }^{1}$ Moscow Technological Institute, 199334, Moscow, Russia
}

\begin{abstract}
This article describes the problems and prospects of introduction of electronic textbooks in the educational space of technical colleges. Practical recommendations for the maintenance, monitoring, organization and development of electronic textbooks projects.
\end{abstract}

\section{Introduction}

Improving quality of education is one of the priority tasks facing modern higher education in Russia. Not by chance the system of indicators of education quality is one of the most developed in the quality management system.

The trend of transformation of library collections currently clearly observed in higher education institutions in the full media centers (electronic libraries, media portals), which are completed of electronic textbooks and manuals.

Electronic textbooks and e-learning resources are becoming one of the most popular components of university information educational environment. Application developers create specialized content for access by mobile devices and personal computers.

Efficient organization of the educational process with the use of electronic textbooks involves the development of new competences of process participants and their active use in combination with modern forms and methods of teaching [1].

Despite the positive trend of the e-books introduction, many users do not understand how to maximize the impact of their use. In the process of technology implementation it is necessary to take into account the fact that electronic books are not only provide economic benefits by replacing traditional textbooks, but also provide a new opportunity to organize educational process.

Today a major role in improving the efficiency and dissemination of successful experience in implementation of electronic textbooks plays the regional education authorities. In various regions there are significant deviations in the dynamics of the use of electronic textbooks and educational complexes. The main emphasis should be placed on the applied nature of the projects, i.e. their realization in the conditions of educational space of higher education, especially technical focus.
On this basis, it is possible to highlight the most important stages of a comprehensive and systematic introduction of electronic textbooks, designed for all participants in the educational process in higher educational institutions:

1. The first step is to analyze the competencies required all participants in the educational process. On that basis the optimum model of work for technical college must be justified.

2. The second stage of the project of introduction of electronic textbooks and complexes the project plan is to be formed and should be described the requirements for the infrastructure creation and for participants (additional supply of technical equipment, in case of need, participants improve their skills), organized the operational control under the efficiency of the project.

Key areas of work are equally important for the effective implementation of the system of electronic textbooks and educational complexes. Let us consider in detail each of them.

\section{Analysis of competences of project participants and rationale of the model}

\subsection{Competence and professional development options}

Effective work of electronic textbooks usage of in the educational process involves a certain degree of readiness of all participants that means they have the necessary information and communicative competence.

The most important role in the final decision on question of how to introduce the system of e-books and educational resources plays a higher educational institution management. That it provides the necessary logistical resources to ensure the smooth implementation of the project

There are several sorts of participants on the all stages of introduction, promotion and e-textbooks usage: - IT-specialists;

\footnotetext{
Corresponding author: kda85@inbox.ru
} 
- media centers personal;

- academic staff [2].

The introduction of electronic textbooks as in most cases the implementation of other information and communication projects begins with the informational and as the most important communicative training participants. Due to it a number of questions arise: what should be taught? What competence will be formed at participants? Whether participants consistent with the objectives and tasks of the designated process?

Now let me turn to their detailed consideration. ITspecialists and system administrators face a number of important tasks for the organization of the process of implementing and maintaining it up to date the electronic textbooks and educational complexes in separate room (laboratory) and throughout the educational institution.

The main competences are the following:

- Skills to install and manage software, e-books on devices with different software platforms including mobile;

- providing access to electronic textbooks and educational resources on the server and user registration skills;

- Server support and LAN.

- Promptly updating and installation of additional content to ensure effective operation of the system;

- coordinating the educational process in the information-educational environment of university;

- diagnosis and elimination of technical problems when working with electronic educational resources.

Teachers and employees of media center (libraries) by virtue of their profession (regular interaction with students) used to practice basic information and communicative competence, but in addition they must possess specific skills and abilities, resulting from their involvement in all stages of implementation of electronic textbooks in the educational area of universities.

The main (basic) competencies include:

- The minimum necessary knowledge of office applications for the compilation of teaching materials and reference of the working documents;

- Ability to organize personal information space and knowledge of graphical interface operating system;

- Basic skills in Internet.

Additional competencies may change over time. Thus, the formation of additional information and communicative competence of employees of libraries and media centers greatly influenced by the federal law «On Education in the Russian Federation», providing for changes in the form of reference library catalogs, library records and communications with students.

This category of workers in the framework of university projects can take part in the installation of electronic textbooks on computers and mobile devices, to advise them on the use of specific textbooks.

Additional competencies should also include:

- Knowledge of legal mechanisms for the application of information Internet resources in education;

- Systematic work with the information space;

- Formation of own electronic portfolio;

- Usage of virtual information space in order to increase the efficiency of work;
- Accounting and working with electronic databases from textbooks and educational complex;

- Organize complex automation of the workplace with different software modules.

This is where most of the universities face significant challenges. Basic library staff was not prepared for the new realities of education. The volume of competencies that need to master the employees in this category was quite large considering the fact that the programs of vocational training, based on information and communication technology were not investigated enough.

The list of additional competencies for the teaching staff will be even wider.

Technical college teacher should be able to work perfectly with the electronic textbooks and a variety of electronic educational resources, applying the technology, taking into account the constantly changing conditions of the university educational space.

Additional teacher competencies include:

- The ability to quickly navigate and organize the search for specific information in an electronic textbook as well as add bookmarks and hyperlinks;

- In the mode of operational interaction with the electronic textbook to get quick access to the basic components (workbooks, fund evaluation tools);

- Connect multimedia demonstration and other modules of the electronic textbook;

- The preservation of the entire job or a part thereof, as well as other resources;

- If necessary, apply the tools of accumulation of additional resources in the textbook environment;

- Modeling elements lectures and practical exercises in the interactive and multimedia environment of the electronic textbook [3].

In addition, teachers must be able to:

- Simulated exercises on a «one student - one unit», as each student works individually electronic textbook on a personal computer, tablet, or other mobile device;

- Actively use information and communication technologies in the formation of the control systems of educational process in the classroom;

- Draw on the best practices in the field of educational technology.

\subsection{Information and communication technologies}

A positive point in the implementation of electronic textbooks is the ability to take into account when they are created virtually all the trends of development of modern educational technology, which gives them additional advantages over traditional paper textbooks, and provides huge potential for their further development and equipping of additional educational modules. The most striking examples of the implementation of these technologies are the following projects:

- Mobile learning on a «one student - one device» which opens students unlimited access to electronic textbooks and educational resources on their personal computers or 
mobile devices without being tied to a specific room of the university;

- Distance learning, promoting the organization of remote interaction of faculty and students in an environment where there is no possibility of full-time presence in the classroom from both sides. This technology is a great outlet for people with disabilities or for those students who want to learn and at the same time working or living at a considerable distance from the educational institution;

- Mixed education which allows combining the elements of the traditional full-time training in a classroom with online technologies implemented in the electronic textbooks. A good example may be the model of the «inverted-class», which implies the development of selfteaching material to students of classes (at home, at work, on a walk, etc.). Occupation acquires seminary (practical) form. Thanks to what the teacher have more free time, which allows him to organize a session on a qualitatively different level. This is especially valuable when conducting classes at students of technical directions.

- Learning with the use of active forms of learning management system in the classroom (LMS). Due to which the teacher can more effectively and efficiently organize the entire process of learning (provided by increasing the motivation and dedication of students during learning);

- Extensive use of students and teachers of cloud technologies, as one of the most important elements of the information-educational environment of high school. The technology successfully solves the problem of licensed software, the organization of unique personal media students and teachers, as well as to improve the efficiency of interaction between them when working with electronic textbooks and educational resources. Sharing e-books with the systems of active learning and educational content management which allows for a number of additional advantages:

- Improving management efficiency of the educational process through the active use of personal computers and mobile devices on the basis of information and communication technologies;

- Providing opportunities for individual tracking of each student, taking into account the degree of development of educational material;

- The development of communication skills and academic cooperation between students and the instructor through extensive networking.

Unlike traditional paper textbooks an electronic textbook is a unique tool that acquires individual traits in the hands of every student. The main task when creating an electronic textbook is to ensure its smooth operation in off-line mode, when there is no Internet connection. At the same time connected to the Internet, should ensure prompt «quiet» textbook update and send to processing server of the results of development of theoretical material and assignments students from the fund evaluation tools.

\section{The project of electronic textbooks in high school}

The introduction of any electronic textbook implies full inclusion of all participants in the project that cannot be done without careful planning, the implementation of a number of preparatory operations and strict regulation of key stages.

\subsection{The process of implementation of the electronic textbook}

The process of implementation of the electronic textbook includes the following steps:

- The process of implementation of the electronic textbook includes the following steps;

- Professional development, and, if necessary, and professional retraining of teachers in the mobile training programs according to the «1 student - 1 device»;

- Operational control and information and methodological support in the implementation of the project;

- Organize regular open sessions with the use of e-books and other electronic educational resources;

- Professional development of teachers for training programs aimed at the formation of additional specific information and communication competencies;

- Analysis of the effectiveness of the project in order to study the results of the use of electronic textbooks (improving learning outcomes of students, the development of information and communication competencies of teachers);

- To develop an algorithm of improving textbooks and guidelines for its use;

- In the case of a positive result of the introduction of the textbook copying experience.

Defining the goals, objectives and content of the project:

- The organization of an expert group on the implementation of the project;

- Conformity assessment of teachers who are ready to use electronic textbooks and new educational technologies;

- Justification for the use of the textbook model;

- Preparation of documentation for the successful operation of the electronic textbook;

- An integrated approach to the organization of student and teacher workspace creation of common for universities infrastructure (access points to connect to a local network and the Internet, configuration and optimization of personal computers and mobile devices to share them).

- Strategic planning of the implementation process of electronic textbooks in high school on the short, medium and long term [4].

\subsection{Improvement the effectiveness of project infrastructure in the educational environment}

Improvement the effectiveness of project infrastructure in the educational environment must meet the following requirements: 
- Presence of a stable educational environment;

- The presence of the media center (library + Information Centre), with free access to the media resources of the university and the electronic library and educational resources;

- Optimal equipment technical equipment (projectors, interactive board, network access points, mobile tablets, etc.) allow the implementation of information and communication technologies;

- Unlimited access to the content for students preparing for classes at a convenient time, from any location;

- The actual software.

Regardless of the shape and pattern of learning electronic textbook will be a versatile educational tool the individual subject to the scheme «one student - one computer». As a result will not only increase the motivation of learning but also a qualitative improvement in storage and later playback of acquired knowledge and skills. This mechanism will be successfully implemented only in the case of wellfunctioning classroom and teaching management system when teacher is not looking up from the workplace and specifically works with students according to the on a «teacher - the whole classroom - an individual approach to each student $\gg[5,6]$.

Feedback makes easier changes in the educational process of all students, focusing his attention on special materials or task.

\subsection{Organizing of monitoring}

Monitoring of process of e-textbooks introduction has great importance enabling to make promptly changes into organizational and educational processes on various stages and evaluate qualitative and quantitative indicators of students' education output.

The following may appear as monitoring objects:

- integrated effect of e-textbooks on qualitative and quantitative indicators of students during independent preparation for studies and as in-class activities;

- selected teaching models and their combinations, additional services and their effect on students' competence and motivation;

- evolution of changes in teaching staff competence.

\subsection{Guiding and development of e-textbooks projects}

Guiding is one of the most essential elements of etextbooks introduction. This process includes equipment of college, improvement of teaching staff competence level, registration of users and opening content access, sharing of successful practices of introduction.

Guiding represents the longest part of process which involves members of all the three categories. The process may be tentatively subdivided into three following stages:

1) Using of e-textbook in teaching process of college. This stage presumes ensuring free access to the textbook and maximum utilization of its potential. Incorporation of electronic educational resources, including textbooks, into informational and educational environment of college encourages not only personal-oriented approach but also activity approach in process of students' teaching.

2) Utilization of e-textbooks in teacher's practice. This stage envisages systematic professional level improvement in the sphere of application e-textbooks and electronic educational resources in teaching process which leads to improvement of information and communication technologies and allows realizing on practice actual educational trends.

3) Introduction of e-textbook into educational process. Critical role on this stage belongs to precise model linked to the students or subject.

Guiding of the present stage involves thorough process planning and application of e-textbook in teaching process of the college with regard to selected model.

4) Introduction of e-textbook into informational and educational environment of college. This stage presumes development of efficient plan of infrastructure engineering in college in order e-textbook project could be realized. Essential requirements to resources' provision of the project are to be determined.

5) Direct use of e-textbooks by the students. Guiding on the stage enables personalizing teaching process for each student with regard to indicators of speed, volume and quality of learning. Here the following factors are to be taken in account by the teacher: level of educational material accessibility; practical knowledge of students' work will electronic content; possibility of on-line tasks fulfillment.

Thus, it is possible to trace certain mechanisms of improvement the efficiency of e-textbooks introduction in technical colleges:

1. Questioning. On each stage of project realization questioning is carried out being mandatory for all the participants. Questioning enables to determine existing bottlenecks and promptly eliminate them or make corrections in educational program.

2. Remote trainings, seminars and practice classes. Are also provided for all the project participants. Depending of level of preparation of participants a list of questions which are recommended for obligatory studying is compiled. This list may be amended at any time based on progress of project realization and exact requirements.

3. Sharing experience of introduction of e-textbooks and educational resources between technical colleges. Purpose of this activity is improvement of education level and students' motivation.

4. Once project of e-textbooks application is introduced in several colleges of the region it is possible to form a regional coordination team which can render timely methodical support for all the project participants.

5. Creating a base of the most successful projects for further experience sharing.

Proof of e-textbook introduction project realization efficiency in college is accurate planning of stages and realization of project as well as join efforts and selfdevelopment of all educational process participants. 
One of the main conditions for the development of information-informative independence of students of the University is a network of educational interaction.

Let's determine the definitions that are important for this work: «network», «educational network», «network cooperation», «network pedagogical impact», «network sectorial educational program».

Involving the sources of potential information, the student forms personal (individual) education network PLN (personal learning network). The learning is doe through many channels as different relations are used to deliver educational material. Development of informative and cognitive independence is one of the key pedagogical tasks for modern education system as the ability to learn something new I more important than current knowledge that we possess (ability to enrich knowledge is more important than the static system of accumulated knowledge) [10].

\section{References}

1. A.A. Andreyev, V.I. Soldatkin, Cloud. of Science, 1, 14 (2013).
2. G.G. Bubnov, E.V. Nikulchev, E.V. Pluzhnik, H. Edu.in Rus., 1, 159(2015).

3. G.G. Bubnov, E.V. Pluzhnik, V.I. Soldatkin, Regulatory support of e-learning in Russia, Cl. of Sci., 2, 5 (2013).

4. E.V. Pluzhnik, E.V. Nikulchev, The functioning of the educational systems in the cloud, Pr. of the Un., 3, (2013).

5. I.V. Osipov, E.V. Nikulchev, A.A. Volinsky, A.Y. Prasikova, Study of gamification effectiveness in online e-learning systems, International Journal of Advanced Computer Science and Applications, 6, 71 (2015).

6. E.V. Bugakova, From the experience of the use of ICT in the educational process of high school, (MTI, Moscow, 2015). 